\title{
Recent progress of thick tungsten coating prepared by chemical vapor deposition as the plasma-facing material
}

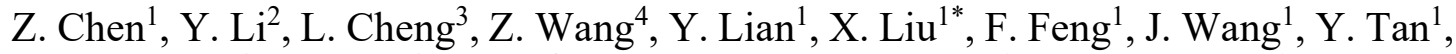
T.W. Morgan ${ }^{2}$, G.H. Lu ${ }^{3}$, X. Ye ${ }^{4}$, B. Yan ${ }^{5}$, J. Song ${ }^{5}$, M. Xu' ${ }^{1}$ and X.R. Duan ${ }^{1}$

${ }^{1}$ Southwestern Institute of Physics, P.O. Box 432, Chengdu 610041, China

${ }^{2}$ DIFFER - Dutch Institute for Fundamental Energy Research, De Zaale 20, 5612 AJ Eindhoven, Netherlands

${ }^{3}$ School of Physics, Beihang University, Beijing 100191, China

${ }^{4}$ Science and Technology on Surface Physics and Chemistry Laboratory, Jiangyou, Sichuan Province, 621908, China

${ }^{5}$ Xiamen Tungsten Co., Ltd., Xiamen 361009, China

*corresponding author: xliu@swip.ac.cn (X. Liu)

\begin{abstract}
Chemical vapor deposition (CVD) is a promising technique for the preparation of $\mathrm{W}$ based plasma-facing materials (PFMs). An overview of the microstructure, chemical composition, thermal conductivity, thermal stability, thermal shock performance under disruption-like and edge localized mode (ELM)-like transient heat load, and neutron irradiation performance of CVD-W has been given in our previous work. However, for fusion applications, additional properties need to be assessed. To this end, deuterium (D) permeability, D plasma irradiation performance, and thermal fatigue resistance of CVD-W were investigated in this work. The results showed that the D permeability of CVD-W in the temperature range of 973-1173 K was larger than that of the commercial pure $\mathrm{W}$, which was related to the columnar grain structure of CVD-W. Additionally, both CVD-W and commercial pure $\mathrm{W}$ were exposed to D plasma up to a fluence of $1 \times$ $10^{26} \mathrm{~m}^{-2}$. Compared to commercial pure $\mathrm{W}, \mathrm{CVD}-\mathrm{W}$ exhibited a mitigated blistering behavior and lower D total retention, which could be attributed to its strong [001] crystallographic texture along the thickness direction and a lower number of defect density (e.g. grain boundaries). CVD-W and commercial pure $\mathrm{W}$ were also exposed to steady-state and transient heat load simultaneously, leading to a base surface temperature and surface temperature increase of about 953-1473 $\mathrm{K}$ and 250-300 K, respectively. A strong grain orientation dependence of the surface degradation induced by the combined heat load has been found. Consequently, CVD-W exhibited a much more uniform plastic deformation than pure $\mathrm{W}$, and no surface cracks along grain boundaries were observed in CVD-W. Finally, the industrial-scale production of CVDW-based PFMs and mockups was demonstrated. This work paves the way for the fusion applications of thick CVD-W coatings.
\end{abstract}

Keywords: PFM, CVD-W, D plasma, heat load, mockups 


\section{Introduction}

In a deuterium-tritium (D-T) future fusion reactor, the plasma-facing materials (PFMs) of the divertor under service will be exposed to high heat flux, high plasma flux, and high energetic neutrons $(14.1 \mathrm{MeV})$, simultaneously. The steady-state heat flux and slow transient events (up to $10 \mathrm{~s}$ ) of the PFMs of the divertor in ITER could be up to $10 \mathrm{MW} \cdot \mathrm{m}^{-2}$ and $20 \mathrm{MW} \cdot \mathrm{m}^{-2}$, respectively [1-4]. This could lead to significant temperature and thermal stress gradient in the plasma-facing components (PFCs). Therefore, selecting materials with high thermal conductivity, high melting point, good irradiation resistance, and excellent mechanical property at elevated temperatures is indispensable.

Tungsten (W) has been regarded as the most promising PFM for fusion reactors. According to the design of the ITER full-W divertor, the surface temperature of the Wbased PFM exposed to $20 \mathrm{MW} \cdot \mathrm{m}^{-2}$ would be above $2000 \mathrm{~K}[1,5,6]$. Such a temperature is higher than the recrystallization temperature of traditional pure $\mathrm{W}(\sim 1600 \mathrm{~K})$. Therefore, microstructure changes induced by recrystallization and grain growth seem unavoidable for the W-based PFM during service [7]. Moreover, according to the material specification of ITER, grains of the PFM should be oriented parallel to the heat flux direction [8] to enhance the heat transfer efficiency. However, the preferentially oriented microstructure could be gradually weakened by the recrystallization-induced equiaxed grains and grain growth. Therefore, strategies that could increase the recrystallization temperature of $\mathrm{W}$ are attracting more and more attention. Previous works showed that dispersion (e.g. oxide and carbide particles) strengthened W alloys have much higher recrystallization temperatures than pure $\mathrm{W}[9,10]$. The recrystallization temperature of $\mathrm{W}$ could also be significantly increased by solution (e.g. rhenium) strengthening [11]. Both of them are usually prepared by powder metallurgy (PM) routes, which consists of powder manufacturing (e.g. mechanical milling and wetchemical method), compacting (e.g cold uniaxial pressing and cold isostatic pressing), sintering (e.g. vacuum heating-press sintering, hot isostatic pressing sintering, and spark plasma sintering), and post-treatment (e.g. hot forging and hot rolling). This route is complex and are usually time-consuming, and machining is unavoidable during the post-manufacture of the PFC. Additionally, the addition of dispersion particles and solution elements could complicate the plasma-material interaction, which would potentially lead to critical concerns about dust production and fuel recycling. For 
example, the formation of $\mathrm{W} / \mathrm{Y}_{2} \mathrm{O}_{3}$ composite, melting, vaporization, and depletion of the $\mathrm{Y}_{2} \mathrm{O}_{3}$ particles have been observed on the plasma exposed $\mathrm{Y}_{2} \mathrm{O}_{3}$ dispersion strengthened $\mathrm{W}[10]$, which will potentially cause plasma contamination if the formed dust were to transport to the core plasma. Therefore, efforts that could improve the service performance of pure W-based PFMs are still needed.

Promising routes for the preparation of pure W-based PFM are coating techniques. Pioneering works on the research and development of physical vapor deposition (PVD) have been performed during the upgrade of the PFM in JET and ASDEX Upgrade [12]. However, the fusion application of the $\mathrm{W}$ coating prepared by this method is limited by its thickness (at micrometer level). For the W-based PFMs of the divertor with a lifetime of 2 full-power years, a thickness of above $5 \mathrm{~mm}$ would be needed [13]. Therefore, it is essential to develop coating techniques with high production efficiency. In the past several years, enormous efforts on the development of coating techniques for the preparation of thick W coatings have been carried out. For example, atmospheric pressure chemical vapor deposition (APCVD) with deposition rates in the range of 0.4$1.0 \mathrm{~mm} / \mathrm{h}$ has been successfully developed at Southwestern Institute of Physics (SWIP, China) and Xiamen Tungsten Co., Ltd (XTC, China) [14]. The prepared CVD-W coating with millimeter thickness has advantages such as high purity, excellent thermal conductivity, and good thermal shock performance, manifesting its great potential for fusion applications. Moreover, even no dispersion particles and solution elements were added, the columnar grain structure of the CVD-W coating was still maintained when annealing at a temperature of $2573 \mathrm{~K}$ for $3 \mathrm{~h}$ [15], indicating its excellent recrystallization resistance. Additionally, CVD has also been used to prepared the $\mathrm{W}$ fiber reinforced $\mathrm{W}\left(\mathrm{W}_{f} / \mathrm{W}\right)$ composite $[16,17]$. Therefore, CVD is a promising candidate for the preparation of W-based PFM for fusion applications.

Recently, an overview of relevant results including its preparation method, microstructure, purity, thermal conductivity, thermal stability, thermal shock performance under disruption-like and edge localized modes (ELM)-like heat fluxes, and neutron irradiation performance in fission reactors of the thick CVD-W coatings has been given [14]. However, there are still some questions to be addressed with respect to application of the CVD-W coatings in fusion. Firstly, in terms of plasmamaterial interaction, the hydrogen $(\mathrm{H})$ isotopes ( $\mathrm{D}$ and $\mathrm{T}$ ) transporting from the scrapeoff layer to the PFM of the divertor in ITER would have an ion flux up to $10^{24} \mathrm{~m}^{-2} \cdot \mathrm{s}^{-1}$. 
Surface degradation (e.g. blistering), and fusion fuel inventory in the PFM and its permeation through it into the coolant are of particular concern during its long-term operation $[18,19]$. So far, there are abundant experimental and simulation results about the $\mathrm{H}$ transport in bulk polycrystalline $\mathrm{W}$ and monocrystalline $\mathrm{W}[18,20,21]$. However, experiments aiming at evaluating the $\mathrm{H}$ transport behaviour of the $\mathrm{W}$ coating which has a distinct microstructure compared to the bulk W (prepared by powder metallurgy) are very limited. Recently, Xu et al. [22] found that the apparent diffusivity and solubility of the $\mathrm{W}$ coating prepared by magnetron sputtering, which also exhibited a columnar grain structure in the thickness direction, were very different from that of the bulk polycrystalline $\mathrm{W}$. Therefore, measuring $\mathrm{H}$ isotope transport parameters including permeability, diffusivity, and solubility of the PFM is of great importance to the nuclear safety analysis and $\mathrm{T}$ recovery system design of fusion reactors. Secondly, heat flux performance of the PFM simultaneously exposed to steady-state and transient heat fluxes is required to fully evaluate its service performance under fusion-relevant heat flux [10]. Therefore, experimental results of D gas-driven permeation (GDP), D plasma irradiation, and high heat flux testing of the CVD-W samples are presented in this work.

\section{Experimental details}

\subsection{Sample preparation and characterization}

Thick CVD-W coatings with thicknesses of $\sim 2.5 \mathrm{~mm}$ on copper $(\mathrm{Cu})$ substrates were supplied by the Xiamen Tungsten Co., Ltd. (China), which was prepared by APCVD using tungsten hexafluoride with a purity of 99.99 wt.\% as W source. The detailed preparation process could be found in Refs. [23-25]. After deposition, the $\mathrm{Cu}$ substrate was chemically etched to get the pure CVD-W coating. Then CVD-W pieces for D GDP, D plasma irradiation, and heat flux testing were cut from the as-received coating by electrical discharge machining (EDM). The top-view and cross-sectional morphologies of the CVD-W were first investigated by optical microscopy after mechanical polishing and etching. The etching was carried out by standard Murakami's solution to reveal grain boundaries. All the polished samples were annealed in a vacuum furnace at $1273 \mathrm{~K}$ for $1 \mathrm{~h}$ to release residual stresses. For the preparation of $\mathrm{W}$-based ITER-like water-cooled monoblocks, CVD-W coatings were deposited on commercial pure $\mathrm{W}$ substrates. Thermal annealing at a temperature of $1773 \mathrm{~K}$ for $2 \mathrm{~h}$ was then performed for residual stress relief and increasing the bonding strength between the 
CVD-W coating and $\mathrm{W}$ substrate.

\subsection{Gas-driven permeation}

D permeability of the CVD-W sample was investigated by a GDP system at the Science and Technology on Surface Physics and Chemistry Laboratory, China. The details of the GDP system have been given in Ref. [26]. In brief, the upstream chamber and downstream chamber of the GDP system were separated by the sample with a thickness of about $0.5 \mathrm{~mm}$. The $\mathrm{D}$ gas pressure of the upstream chamber was monitored by a capacitance diaphragm gauge (PMA Transmitter P40). Before testing, the downstream chamber was kept under a high vacuum, which had a background pressure of the order of $\sim 10^{-6} \mathrm{~Pa}$. The sample was first heated to the desired temperature in the range of 973 $\mathrm{K}$ to $1073 \mathrm{~K}$ by a furnace. Then $\mathrm{D}$ gas was filled up in the upstream chamber to a pressure of $100 \mathrm{kPa}$. The signal of $\mathrm{D}$ that permeated to the downstream chamber through the sample was measured by a quadrupole mass spectrometer (QMS, PFEIFFER QMG 422I) which had been calibrated by a series of standard leaks. For comparison, a sample cut from a commercial pure W plate with a purity of $99.99 \%$ supplied by the Advanced Technology \& Materials Co., Ltd. (China), which was produced by powder sintering followed by rolling with a thickness reduction of $\sim 75 \%$, was also tested under the same conditions.

\subsection{D plasma irradiation}

To investigate the D plasma irradiation resistance of the CVD-W, the prepared CVDW samples were exposed to low energy, high flux D plasma in Magnum-PSI [27, 28]. Three CVD-W samples annealed at temperatures of $1273 \mathrm{~K}$ (C-1-1), $1773 \mathrm{~K}$ (C-1-2), $2373 \mathrm{~K}(\mathrm{C}-1-3)$ for $1 \mathrm{~h}$ were exposed. For comparison and to investigate the effect of grain boundary density on the $\mathrm{D}$ plasma irradiation performance, a commercial pure $\mathrm{W}$ sample annealed at $1773 \mathrm{~K}$ for $1 \mathrm{~h}(\mathrm{R}-1-1)$ was also exposed to the same D plasma. The samples were fixed on a water-cooled sample holder and exposed to D plasma at normal incidence. Electron temperature and density of the plasma were measured by a Thomson Scattering (TS) system [29] 30 mm in front of the target. For each sample, 3 separate measurements with an interval time of $3 \mathrm{~s}$ were taken by the TS system. During exposure, a negative bias of $-50 \mathrm{~V}$ was applied to the target. The sample temperature was about $823 \mathrm{~K}$, measured by a fast-infrared camera (IR-cam, FLIR SC7500MB), which was calibrated by a spectropyrometer (FAR Associates ${ }^{\circledR}$ ) in the 
wavelength range of 900-1700 $\mathrm{nm}[30]$.

Figure 1 shows the average electron temperature $\left(T_{e}\right)$ and density $\left(n_{e}\right)$ of the D plasma. The average peak electron temperature and density were $\sim 1.65 \mathrm{eV}$ and $\sim 4.73 \times 10^{19} \mathrm{~m}^{-}$ ${ }^{3}$, respectively. The exposed duration of each sample was $300 \mathrm{~s}$, corresponding to a peak fluence of $\sim 1.02 \times 10^{26} \mathrm{~m}^{-2}$ when evaluating with a collision-less sheath model [31].

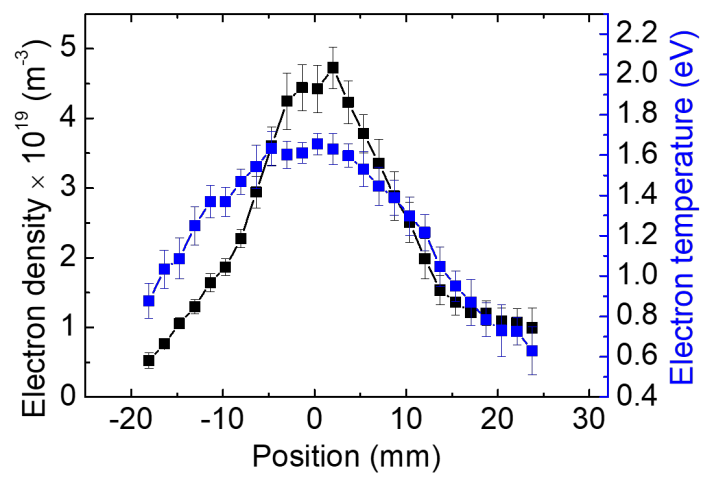

Figure 1. Electron temperature $\left(T_{e}\right)$ and density $\left(n_{e}\right)$ profiles of the D plasma measured by Thomson Scattering $30 \mathrm{~mm}$ in front of the target. The average peak electron temperature and density were $\sim 1.65 \mathrm{eV}$ and $\sim 4.73 \times 10^{19} \mathrm{~m}^{-3}$, respectively.

After exposure, D desorption and retention in the exposed samples were investigated by thermal desorption spectroscopy (TDS) at Beihang University [32]. The ramping rate and maximum temperature of the TDS were $1 \mathrm{~K} \cdot \mathrm{s}^{-1}$ and $1373 \mathrm{~K}$, respectively. A W-Re thermocouple was used to measure the temperature of the sample. An MKS quadrupole mass spectrometer was used to record the $\mathrm{D}$ signal from both $\mathrm{HD}$ and $\mathrm{D}_{2}$ during the heating process, the absolute sensitivity of which was calibrated using a standard leak (VTI).

\subsection{Steady-state and transient heat flux exposure}

The PFM of the divertor under service will be exposed to steady-state and transient heat fluxes, simultaneously. Therefore, to evaluate the thermal fatigue performance of the CVD-W coatings, samples with a diameter of $20 \mathrm{~mm}$ and thickness of $1 \mathrm{~mm}$ were exposed to simultaneous steady-state and transient heat load in Magnum-PSI [27, 28]. CVD-W coatings annealed at temperatures of $1673 \mathrm{~K}(\mathrm{C}-2-1)$ and $1873 \mathrm{~K}$ (C-2-2 and C-2-3) for $1 \mathrm{~h}$ were performed. For comparison, commercial pure $\mathrm{W}$ samples with the same annealing conditions were exposed to the same plasma. Sample R-2-1 was annealed at $1673 \mathrm{~K}$ for $1 \mathrm{~h}$, samples R-2-2 and R-2-3 were annealed at $1873 \mathrm{~K}$ for $1 \mathrm{~h}$. 
The steady-state heat flux was enabled by H plasma, whereas the transient heat flux was supplied by a $1064 \mathrm{~nm} \mathrm{Nd:YAG} \mathrm{laser} \mathrm{(LASAG} \mathrm{FLS} \mathrm{352-302).} \mathrm{Two} \mathrm{batches} \mathrm{of}$ plasma exposure were performed by adjusting the $\mathrm{H}$ gas flow and magnetic field, resulting in base temperatures ( $T_{\text {base }}$ ) of $\sim 953 \mathrm{~K}$ and $\sim 1473 \mathrm{~K}$, respectively. The pulse duration and repetition rate of the laser beam were $1 \mathrm{~ms}$ and $10 \mathrm{~Hz}$, respectively. The total number (\#) of laser pulses of each sample was 10000 . The laser beam has a fullwidth half-maximum (FWHM) of $\sim 4 \mathrm{~mm}$, and an angle of incidence of $\sim 51^{\circ}$ was used. This experimental setup, e.g. target surface temperature measurement was detailed in Ref. [30].

\section{Results and discussion}

\subsection{Microstructure characterization and D permeability}
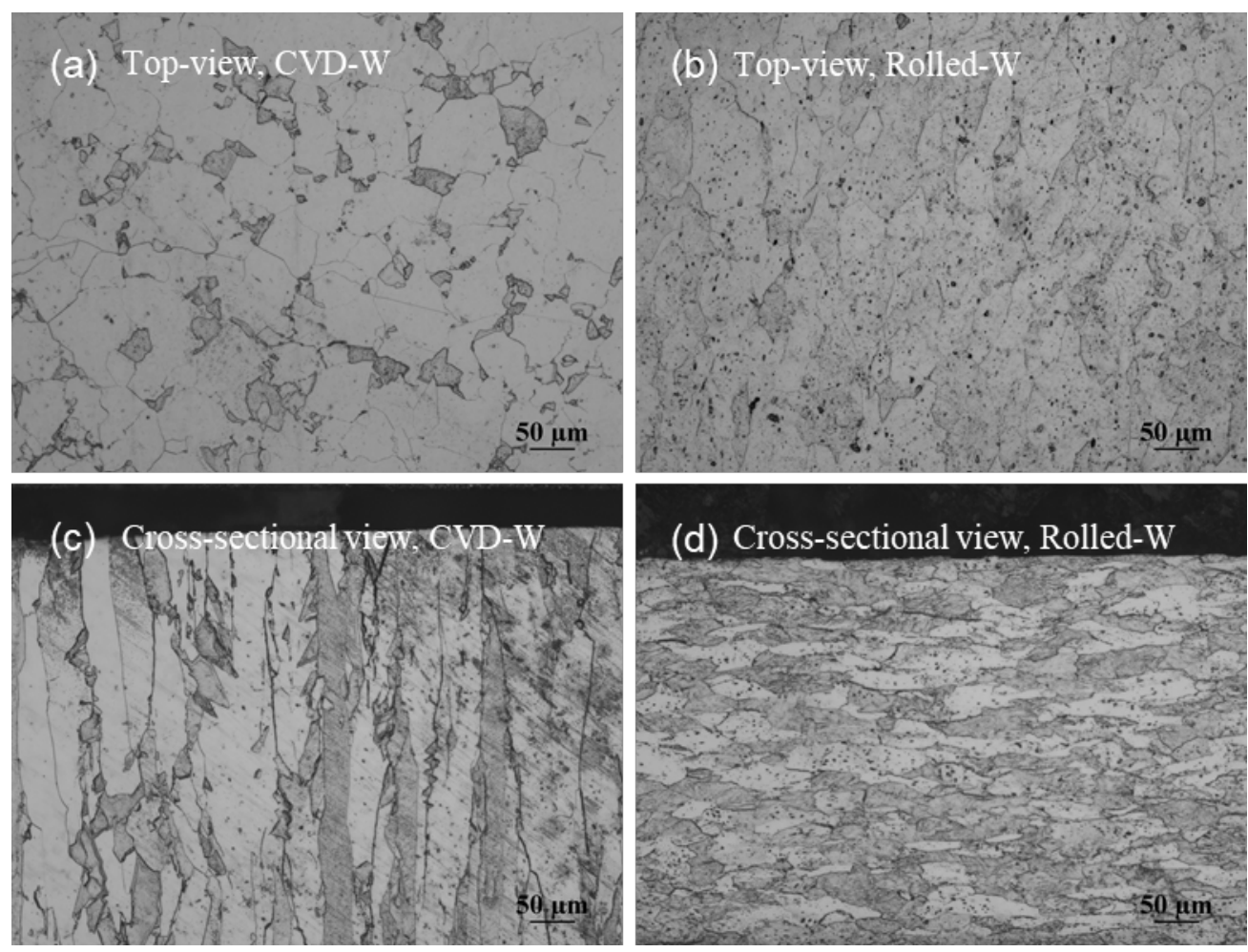

Figure 2. Top-view (a)/(b) and cross-sectional view (c)/(d) of the CVD-W and commercial pure $\mathrm{W}$ samples, respectively. The average grain sizes of CVD-W and commercial pure W (Rolled-W) are $\sim 50 \mu \mathrm{m}$ and $30 \mu \mathrm{m}$, respectively.

Figure 2(a) shows the optical micrograph (OM) of the top-view of the polished CVD$\mathrm{W}$ after etching, the average grain size of which was $\sim 50 \mu \mathrm{m}$. The cross-sectional image of the CVD-W is shown in Figure 2(c). The grains of CVD-W are elongated along the sample thickness direction, manifesting as a columnar structure with an average grain 
width of $\sim 50 \mu \mathrm{m}$. Our previous results [15] demonstrated that no obvious grain growth of the CVD-W coating was observed even annealing up to $1773 \mathrm{~K}$, exhibiting higher thermal stability than the commercial pure W [33]. The top-view and cross-sectional view of the commercial pure W counterpart are shown in Figures 2(b) and 2(d), respectively. Compared to the CVD-W, a finer microstructure with an average grain size of $\sim 30 \mu \mathrm{m}$ is observed. The commercial pure $\mathrm{W}$ exhibits a typically laminated microstructure consisted of elongated grains along the rolling direction.
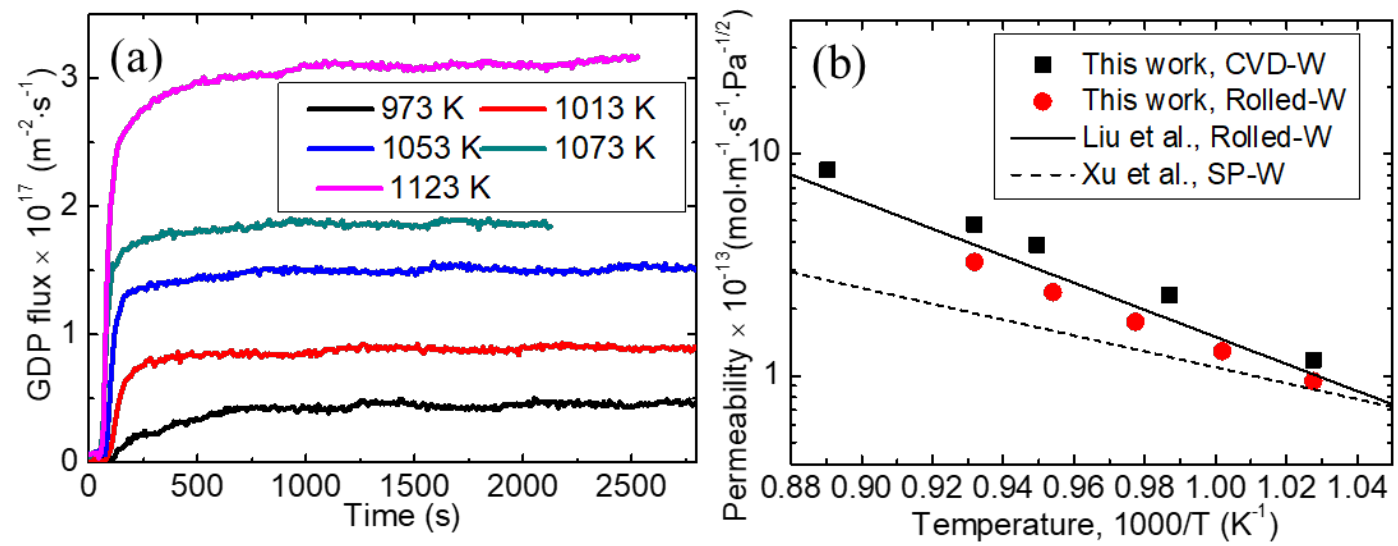

Figure 3. (a) D GDP curves of the CVD-W as functions of time in the temperature range of 973-1123 K, (b) D permeability of the CVD-W and commercial pure $\mathrm{W}$ (Rolled-W) tested at temperatures in the range of 973-1173 K. Results from Ref. [34] (Liu et al.) and Ref. [22] (Xu et al.) are plotted for comparison.

Figure 3(a) shows the D GDP flux curves of the CVD-W sample as functions of time in the temperature range of 973-1123 K. The steady-state GDP flux increases significantly with the increase of testing temperature. For example, the steady-state D GDP flux of the CVD-W at $1123 \mathrm{~K}$ is about $3.0 \times 10^{17} \mathrm{~m}^{-2} \cdot \mathrm{s}^{-1}$, which is about 10 times higher than the one at $973 \mathrm{~K}$. Moreover, the lag time for the steady-state GDP flux decreased significantly with the increase of temperature.

The detailed theory on the determination of $\mathrm{D}$ diffusive transport parameters has been given in Ref. [26], where the same GDP system was used. In brief, permeability $(\Phi)$ can be expressed as:

$$
\Phi=\frac{L_{H D+D_{2}} d}{R T A P}
$$

where $L_{H D+D_{2}}$ is the sum of $\mathrm{D}$ leak rate contributed from $\mathrm{HD}$ and $\mathrm{D}_{2}, P$ is the $\mathrm{D}$ gas pressure in the upstream chamber, $R$ is the regular gas constant, $d$ is the thickness, $A$ is 
the effective area, and $T$ is the temperature of the sample, respectively.

Figure 3(b) shows the D permeability $(\Phi)$ of the CVD-W coating and commercial pure $\mathrm{W}$ in the temperature range of 973-1173 $\mathrm{K}$ according to equation (1). The results in Refs. [22, 34] are also plotted for comparison. Using the Arrhenius formula, the temperature dependence of $\mathrm{D}$ permeability of the CVD-W coating and commercial pure $\mathrm{W}$ are expressed by:

$$
\Phi_{C V D-W}=1.44 \times 10^{-7} \exp \left(-\frac{1.17 \mathrm{eV}}{k T}\right), \mathrm{mol} \cdot \mathrm{m}^{-1} \cdot \mathrm{s}^{-1} \cdot \mathrm{Pa}^{-1 / 2},
$$

and

$$
\Phi_{\text {rolled }-W}=7.14 \times 10^{-8} \exp \left(-\frac{1.14 \mathrm{eV}}{k T}\right), \mathrm{mol} \cdot \mathrm{m}^{-1} \cdot \mathrm{s}^{-1} \cdot \mathrm{Pa}^{-1 / 2}
$$

where $k$ is the Boltzmann constant. D permeability of the CVD-W coating was higher than that of the commercial pure $\mathrm{W}$ counterpart. However, the activation energy for the D permeability of the CVD-W coating was comparable to that of the commercial pure $\mathrm{W}(1.17 \mathrm{eV}$ vs. $1.14 \mathrm{eV})$.

Generally speaking, lattice defects such as vacancies, dislocations, and grain boundaries act as $\mathrm{H}$ traps, leading to the increase of the effective solubility and decrease of the diffusivity of $\mathrm{H}$ in $\mathrm{W}$. So far, there is no consistent conclusion about the effect of grain boundary on the transport parameters. For example, some works [35-37] showed that grain boundaries could act as strong trapping sites for $\mathrm{H}$, entailing a decreased diffusion rate for $\mathrm{H}$ in polycrystalline materials. However, some studies [38, 39] found that grain boundaries may act as fast transport channels for $\mathrm{H}$ by short-circuiting diffusion, leading to an enhanced diffusion rate in polycrystalline materials. Our results indicate that the D permeability of the CVD-W coating with grain boundaries parallel to the transport direction (i.e., thickness direction) was larger than that of the commercial pure $\mathrm{W}$ with a net-like grain boundary structure, even their activation energy values were almost the same. The influence of grain structure on the $\mathrm{H}$ permeability should be considered in the development of advanced PFMs.

\subsection{Blistering and retention}



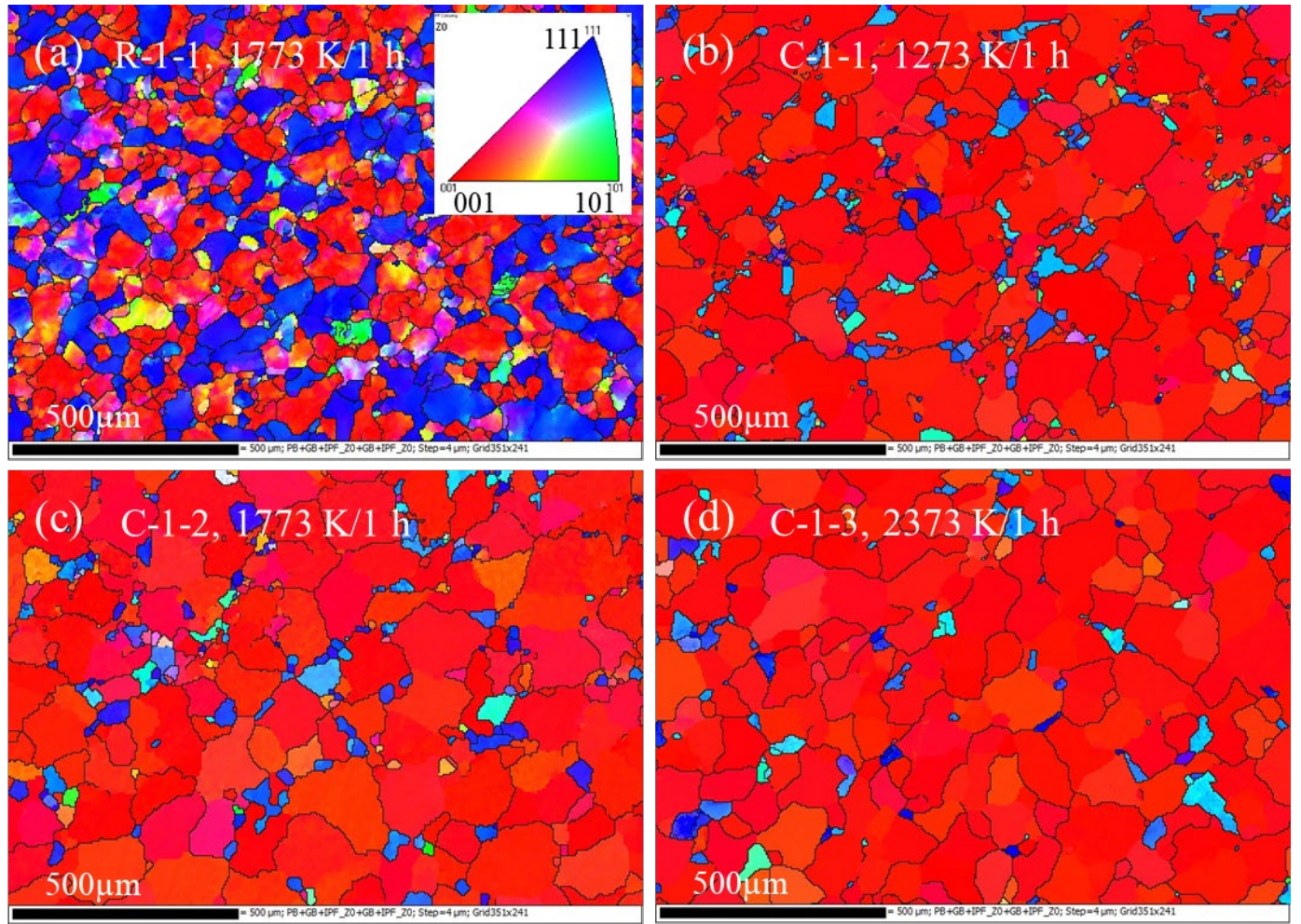

Figure 4. Thickness direction projected inverse pole figure (IPF) maps of the (a) commercial pure W (R-1-1), CVD-W samples with annealing temperatures at (b) 1273 $\mathrm{K}$ (C-1-1), (c) $1773 \mathrm{~K}$ (C-1-2), and (d) 2373 (C-1-3) for $1 \mathrm{~h}$, respectively. The average grain sizes of (b) and (d) are $\sim 50 \mu \mathrm{m}$ and $75 \mu \mathrm{m}$, respectively.

15 , 23]. The results showed that the polished CVD-W sample exhibited a strong [001] texture along the thickness direction, which is consistent with the EBSD results as shown in figure 4 . In contrast, small grains $(<50 \mu \mathrm{m})$ are oriented close to the [111] direction. The CVD-W annealed at $1273 \mathrm{~K}$ also has an average grain size of $\sim 50 \mu \mathrm{m}$ although the large grains are dominated in area, due to the relatively large number of small grains with sizes less than $50 \mu \mathrm{m}$. Grain growth of the small grain could be 
observed when the annealing temperature was $1773 \mathrm{~K}$. However, there was also a considerable fraction of small grains although the annealing temperature was larger than the recrystallization temperature of traditional pure $\mathrm{W}$ [40]. The fraction of small grains in the CVD-W annealed at $2373 \mathrm{~K}$ was decreased obviously, accompanied by grain growth from $50 \mu \mathrm{m}$ to $75 \mu \mathrm{m}$. This indicates that the CVD-W sample has excellent thermal stability, particularly in the resistance of grain growth, which is consistent with our previous work [15]. This could be due to two factors: 1) compared to the as-rolled or forged $\mathrm{W}$, the stored (strain) energy in the CVD-W sample is low; 2) grain growth perpendicular to the thickness direction could be effectively confined by the adjacent grains due to its columnar structure.

Figure 5(a) shows the surface morphology of the R-1-1 sample exposed to D plasma irradiation. D blisters with diameters less than $1 \mu \mathrm{m}$ in round shapes can be observed. However, the distribution of blisters on the surface is not uniform, indicating preferential blistering on some grains. The blistering behavior of $\mathrm{W}$ exposed to He and D plasma and ion has been investigated for many years. Results show that the extent of blistering of W closely depends on grain orientation [41-44]. Blistering preferentially formed on surface grains oriented close to the [111] direction while rarely occurred on grains oriented close to the [001] direction. According to figure 4(a), the commercial pure $\mathrm{W}$ shows a preferred crystallographic orientation along the [001] and [111] directions. Therefore, it is reasonable to find the non-uniform distribution of blisters. Note that the corresponding EBSD maps of the SEM images in figure 5 at the same locations were not provided. However, according to literature (e.g. Ref. [41-44]), it is safe to state that the non-uniform distribution of blisters was due to the difference in grain orientation.

As shown in figure 5(c)-(d), flat blisters or exfoliation instead of circular blisters are observed. Recently, Jia et al. [43] investigated the blistering behavior of CVD-W exposed to D plasma with a peak flux and fluence of $1.5 \times 10^{24} \mathrm{~m}^{-2} \cdot \mathrm{s}^{-1}$ and $0.8-1.1 \times$ $10^{26} \mathrm{~m}^{-2}$, respectively. They also found that the CVD-W sample exhibited good resistance to blistering due to its strong [001] crystallographic texture, even the plasma exposure temperature $(563 \mathrm{~K})$ in Ref. [43] was lower than that in this work. The CVDW samples used in this work and those in Ref. [43] were prepared by the same manufacturing technology. As such, it is reasonable to find that the blistering formation was mitigated in the CVD-W samples in this study. 
(a) $\mathrm{R}-1-1,1773 \mathrm{~K} / 1 \mathrm{~h}$

\section{$10 \mu \mathrm{m}$}

(c) $\mathrm{C}-1-1,1273 \mathrm{~K} / 1 \mathrm{~h}$

$10 \mu \mathrm{m}$ (b) $\mathrm{R}-1-1,1773 \mathrm{~K} / 1$ ก

$1 \mu \mathrm{m}$

(d) $\mathrm{C}-1-3,2373 \mathrm{~K} / 1 \mathrm{~h}$
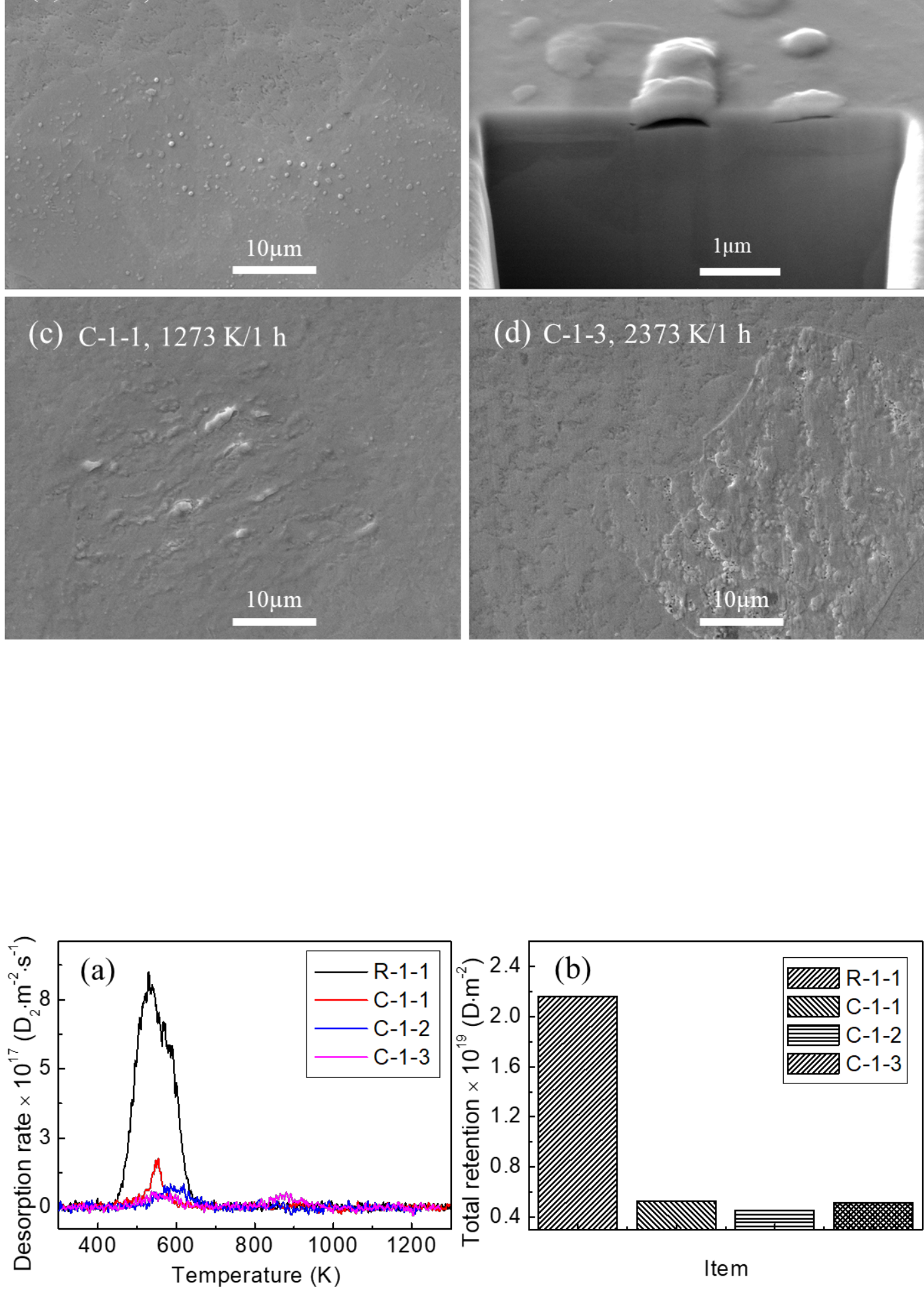

TDS spectra $\left(\mathrm{D}_{2}\right.$ signal) of the commercial pure $\mathrm{W}$ and CVD-W annealed at different 
temperatures are shown in Figure 6(a). Figure 6(b) shows the corresponding total D retention derived from the summary of $\mathrm{HD}$ and $\mathrm{D}_{2}$ signals. A single desorption peak at about $536 \mathrm{~K}$ could be observed for the commercial pure sample, and the total D retention was about $2.16 \times 10^{19} \mathrm{~m}^{-2}$. The total retention is similar to the results in Ref. [45], where the rolled tungsten samples were exposed between temperatures of $943 \mathrm{~K}$ and $1073 \mathrm{~K}$. However, recent results show that the total retention in $\mathrm{W}$ is affected by several factors. For example, Doerner et al. [46] investigated the dependence of D retention in ITER-grade $\mathrm{W}$ exposed to $\mathrm{D}$ plasma up to a maximum fluence of $2 \times 10^{28}$ $\mathrm{m}^{-2}$. The ion energy, ion flux, and sample temperature were $50 \mathrm{eV}, 1.6 \times 10^{23} \mathrm{~m}^{-2} \cdot \mathrm{s}^{-1}$, and $640 \mathrm{~K}$, respectively. They found that the total retention scaled with the square root of the fluence. Plasma flux and sample temperature also affect the total retention significantly $[47,48]$. Therefore, a direct comparison of the total retention of different experiments is challenging.

For the CVD-W sample annealed at $1273 \mathrm{~K}$, the location of the desorption peak was almost the same as that of the commercial pure W counterpart. However, the total D retention in the CVD-W was only $5.28 \times 10^{18} \mathrm{~m}^{-2}$, which was about a quarter of that in the commercial pure $\mathrm{W}$ exposed to the same plasma. According to figure 4 , the number of grain boundaries in CVD-W is fewer than that of the commercial pure $\mathrm{W}$. Additionally, the CVD-W exhibited a high density, excellent thermal conductively as shown in our previous work [14]. Defects and grain boundaries could act as barriers to heat transfer. The high thermal conductivity also means that the number of defects and grain boundaries in the CVD-W were limited. Therefore, the much lower D retention in the CVD-W could be due to the much lower density of defects such as grain boundaries in the CVD-W sample. The desorption peaks of the CVD-W annealed at $1773 \mathrm{~K}$ increased to above $600 \mathrm{~K}$, indicating higher binding energy between $\mathrm{D}$ and defects. Moreover, the total $\mathrm{D}$ retention decreased to $4.56 \times 10^{18} \mathrm{~m}^{-2}$. This is consistent with the results in figure 4, where grain growth of small grains with diameters less than $50 \mu \mathrm{m}$ occurred, leading to the decrease of lattice defects in the CVD-W and consequently the decrease of $\mathrm{D}$ retention. Interestingly, two desorption peaks $(570 \mathrm{~K}$ and $878 \mathrm{~K}$, respectively) could be observed for the CVD-W sample annealed at 2373 K. Recently, Lian et al. [15] found that bubbles near grain boundaries formed in the CVD-W samples annealed at $2573 \mathrm{~K}$ for $3 \mathrm{~h}$ due to the diffusion of vacancies and gaseous impurities at such a high temperature. Although a lower annealing temperature 
$(2373 \mathrm{~K})$ and shorter annealing time $(1 \mathrm{~h})$ were adopted in this work, the formation, diffusion, and coalescence of vacancies were still possible. As such, the high desorption peaks at $878 \mathrm{~K}$ may be attributed to the $\mathrm{D}$ trapping at vacancies. Moreover, the total retention of $\mathrm{D}$ in this sample was about $5.13 \times 10^{18} \mathrm{~m}^{-2}$, which was larger than that in the CVD-W annealed at $1773 \mathrm{~K}$, although obvious grain growth also occurred. The increase of $\mathrm{D}$ retention due to the occurrence of extra trapping site could not be balanced by the decrease of $\mathrm{D}$ retention due to grain growth, leading to the increase of $\mathrm{D}$ retention.

\subsection{Steady-state and transient heat flux}
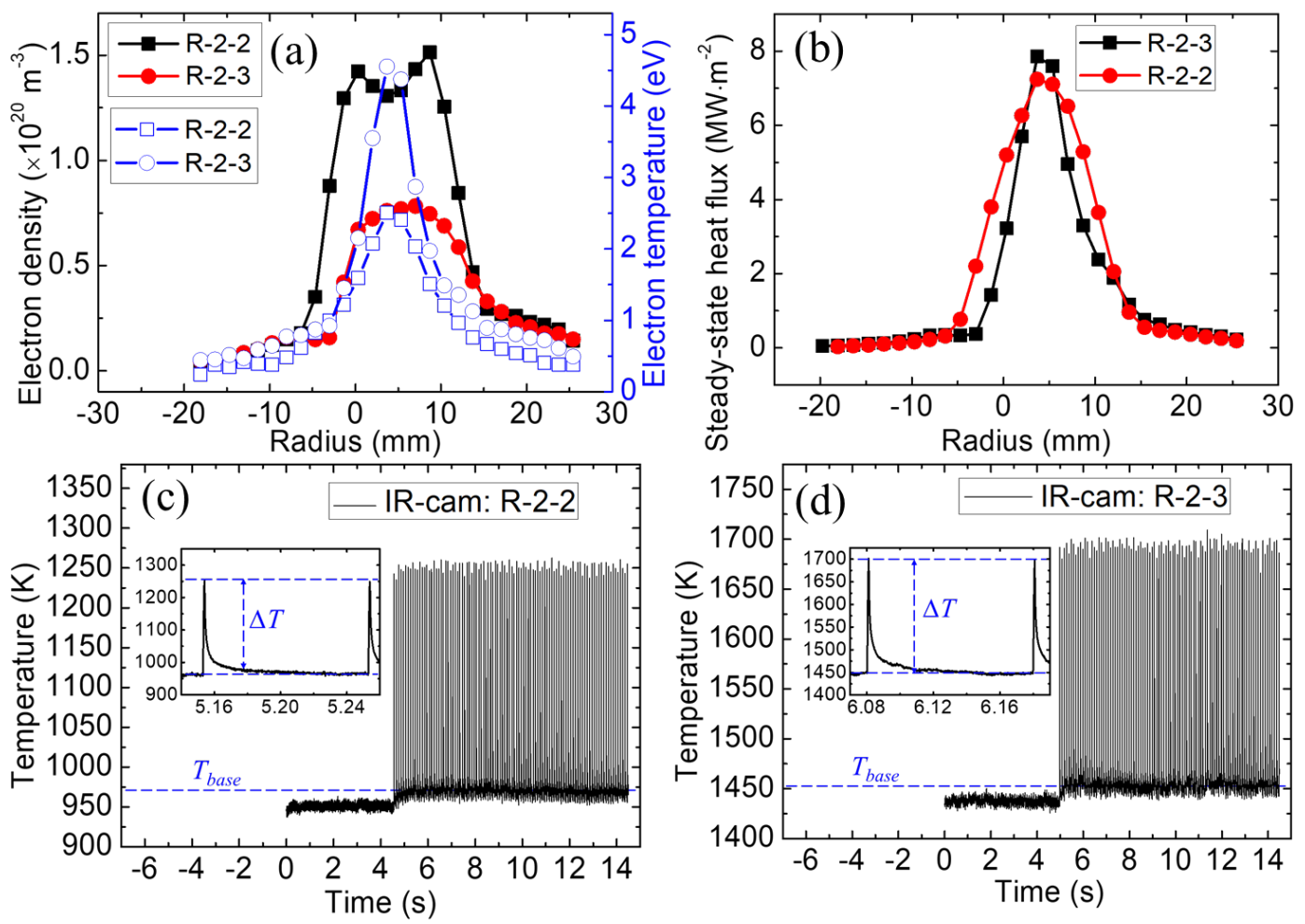

Figure 7. (a) Radial distributions of $T_{e}$ and $n_{e}$ of the H plasma for the R-2-2 and R-2-3 sample exposure. (b) The corresponding heat flux profiles. (c) and (d) show the surface temperature of the R-2-2 and R-2-3 samples, respectively, captured at the laser beam center by the IR-cam. The inserted figures in (c) and (d) show the corresponding temperature spikes induced by the transient heat loads.

Two batches of steady-state and transient heat flux exposures were performed, where samples named C-2-1, C-2-2, R-2-1, and R-2-2 were classified as the first batch, while samples named C-2-3 and R-2-3 were classified as the second batch. Figure 7(a) shows the representative radial distributions of $T_{e}$ and $n_{e}$ of the steady-state $\mathrm{H}$ plasma. For the first batch, the $T_{e}$ and $n_{e}$ located at the beam center were $\sim 2.4 \mathrm{eV}$ and $\sim 1.33 \times 10^{20} \mathrm{~m}^{-3}$, 
respectively. The corresponding steady-state heat flux $\left(q_{\text {steady-state }}\right)$ and $T_{\text {base }}$ of the sample were about $6.5 \mathrm{MW} \cdot \mathrm{m}^{-2}$ (figure 7(b)) and $953 \mathrm{~K}$ (figure 7(c)), respectively. The $q_{\text {steady-state }}$ was calculated according to the Bohm criterion [31]. For the detailed calculation process of $q_{\text {steady-state, }}$ see Refs. [10, 30, 49]. For the second batch, the $T_{e}$ and $n_{e}$ located at the beam center were $\sim 4.6 \mathrm{eV}$ and $\sim 7.7 \times 10^{19} \mathrm{~m}^{-3}$, respectively, corresponding to a steady-state heat flux of $\sim 7.9 \mathrm{MW} \cdot \mathrm{m}^{-2}$ (figure 7(b)). The resulted $T_{\text {base }}$ of the sample was about $1473 \mathrm{~K}$. Figure 7(c) and (d) show the surface temperature evolution of R-2-2 and R-2-3, respectively. The real-time temperature was measured at the laser beam center by the fast IR-cam. The temperature evolution between two pulses was also inserted in figures $7(\mathrm{c})$ and $7(\mathrm{~d})$. The temperature increase $(\Delta T)$ induced by the laser of the two batches were about $300 \mathrm{~K}$ and $250 \mathrm{~K}$, corresponding to a heat flux factor of about $5 \mathrm{MW} \cdot \mathrm{m}^{-2} \cdot \mathrm{s}^{0.5}$ and $4 \mathrm{MW} \cdot \mathrm{m}^{-2} \cdot \mathrm{s}^{0.5}$, respectively [50]. Table 1 summarizes the experimental conditions of the six samples. The plasma parameters and surface temperatures of the samples in Table 1 were measured at the plasma beam and laser beam centers, respectively.

Table 1. Experimental conditions of the exposed CVD-W coatings and pure $\mathrm{W}$ counterparts.

\begin{tabular}{|c|c|c|c|c|c|}
\hline $\begin{array}{l}\text { Sample } \\
\text { name }\end{array}$ & $T_{\text {base }}(\mathrm{K})$ & $\begin{array}{l}\Delta T \\
(\mathrm{~K})\end{array}$ & $\begin{array}{l}\text { Transient heat flux } \\
\left(\mathrm{MW} \cdot \mathrm{m}^{-2} \cdot \mathrm{s}^{0.5}\right)\end{array}$ & $\begin{array}{l}\text { Steady-state heat } \\
\text { flux }\left(\mathrm{MW} \cdot \mathrm{m}^{-2}\right)\end{array}$ & $\begin{array}{c}\text { Pulses } \\
(\#)\end{array}$ \\
\hline C-2-1 & 963 & \multirow{4}{*}{$300 \pm 4$} & \multirow[t]{4}{*}{ ( } & \multirow{4}{*}{6.5} & \multirow{6}{*}{$1 \times 10^{4}$} \\
\hline C-2-2 & 953 & & & & \\
\hline $\mathrm{R}-2-1$ & 948 & & & & \\
\hline R-2-2 & 955 & & & & \\
\hline C-2-3 & 1443 & \multirow[t]{2}{*}{$250 \pm 4$} & \multirow{2}{*}{4} & \multirow{2}{*}{7.9} & \\
\hline $\mathrm{R}-2-3$ & 1473 & & & & \\
\hline
\end{tabular}



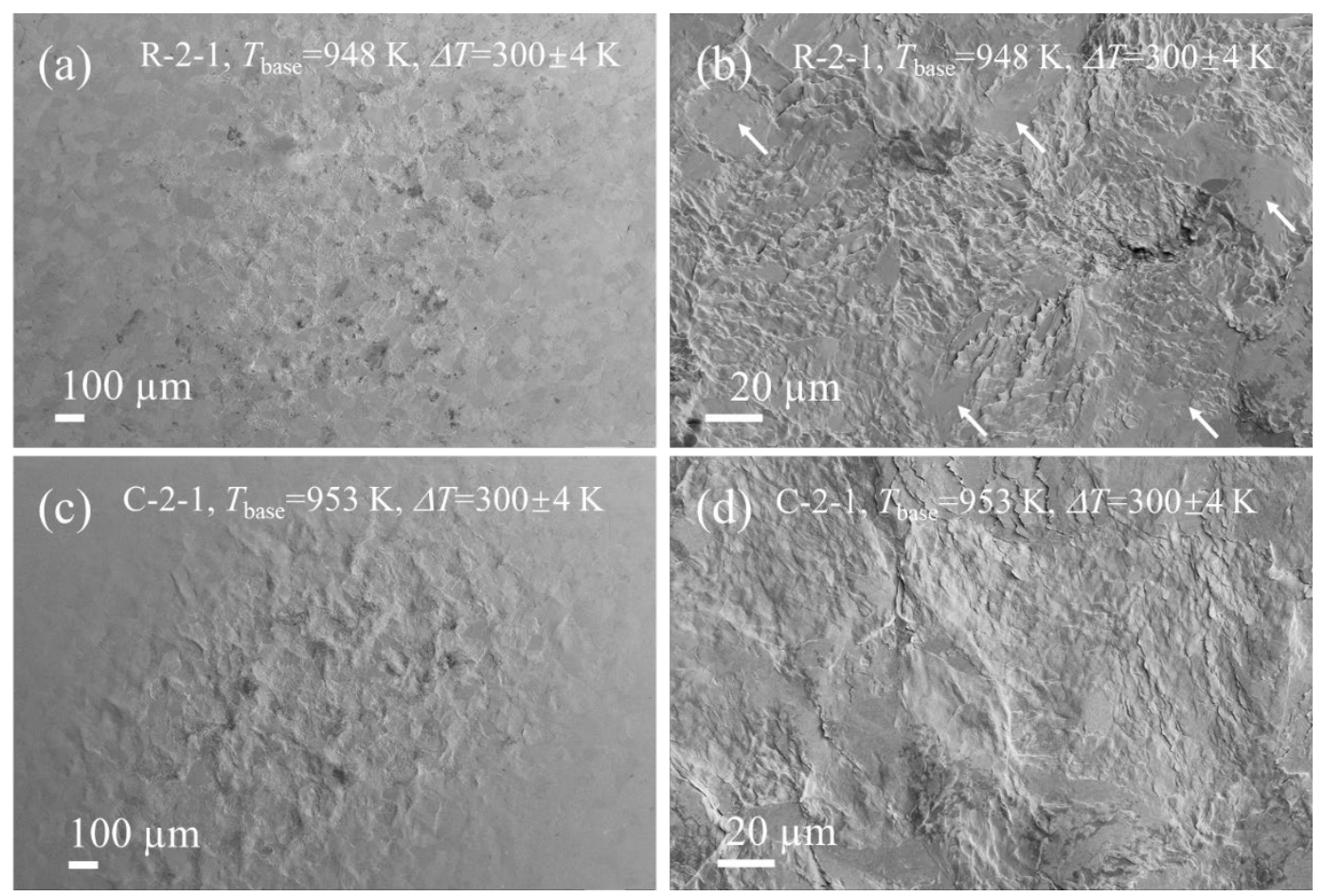

Figure 8. Overview of the surface morphologies of the exposed R-2-1 (a) and C-2-1 (c). (b) and (c) show the corresponding SEM images on the laser beam center of (a) and (c), respectively. $T_{\text {base }}$ and $\Delta T$ of the R-2-1 were $948 \mathrm{~K}$ and $300 \pm 4 \mathrm{~K}$, respectively. $T_{\text {base }}$ and $\Delta T$ of the R-2-1 were $953 \mathrm{~K}$ and $300 \pm 4 \mathrm{~K}$, respectively. $T$ base was induced by the steady-state $\mathrm{H}$ plasma, while $\Delta T$ was induced by the laser beam.

Figure 8(a) shows the overview of the surface morphology of the exposed sample R-21. An elliptical region with obvious plastic deformation (roughness) could be observed. The area of this region was about $1.3 \times 2.0 \mathrm{~mm}^{-2}$. Figure $8(\mathrm{~b})$ shows the highmagnification SEM image of the exposed sample R-2-1, captured at the center of the elliptical region in figure 8(a). Protrusions could be observed on the surfaces of grains. Further examination indicates that the surface deformation was non-uniform, as indicated by the white arrows in figure 8(b). Figure 8(c) and figure 8(d) show the SEM images of sample C-2-1 under the same exposure condition. Compared to sample R-21 , the surface modification was relatively uniform, although protrusions could also be found on the surface grains. According to the EBSD results shown in figure 4, the CVD$\mathrm{W}$ exhibits a strong texture along the [001] direction contributing to the observed uniform surface deformation. The results indicate that the plastic deformation of surface grains under heat flux loading could exhibit a strong grain orientation dependence. 

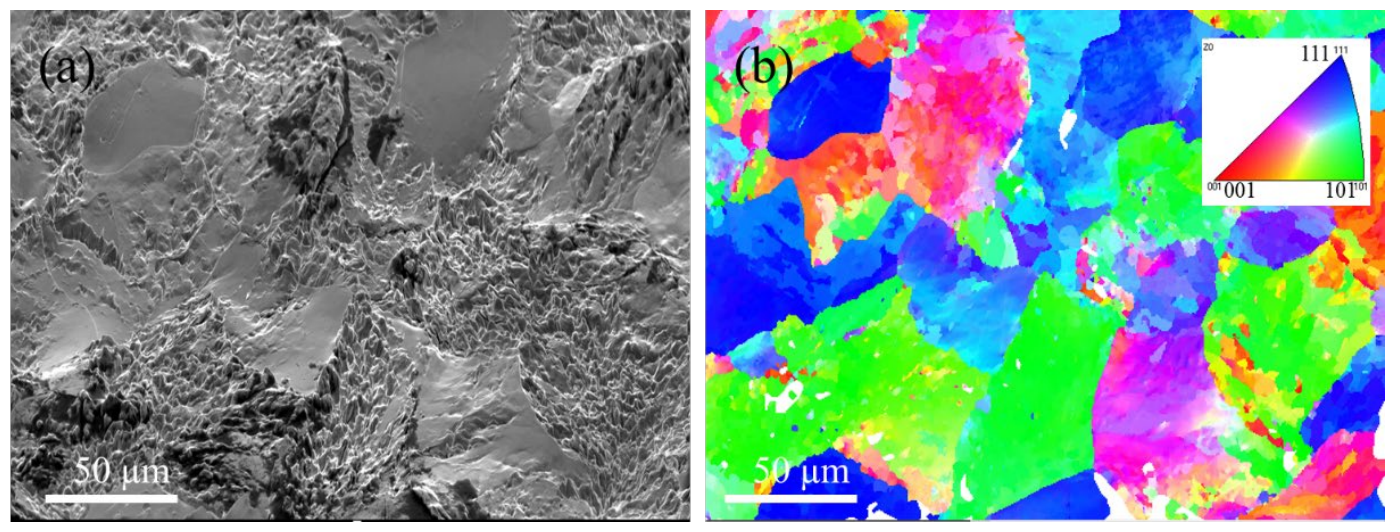

Figure 9. (a) SEM and (b) the corresponding IPF map of the exposed R-2-2 captured at the laser beam center (color key inserted). $T_{\text {base }}$ and $\Delta T$ of the R-2-2 were $955 \mathrm{~K}$ and $300 \pm 4 \mathrm{~K}$, respectively. $T_{\text {base }}$ was induced by the steady-state $\mathrm{H}$ plasma, while $\Delta T$ was induced by the laser beam.

To reveal the grain orientation dependence of the surface degradation induced by the heat flux loading, a commercial pure W sample (R-2-2) that is annealed at $1827 \mathrm{~K}$ for $1 \mathrm{~h}$ was exposed to the same heat flux loading. Figure 9(a) shows the corresponding surface morphology at the laser beam center, which is non-uniform. Additionally, EBSD analysis were performed on the same area as shown in figure 9(b). It is observed that plastic deformation preferentially occurs on the surface grains with normal directions close to [101].
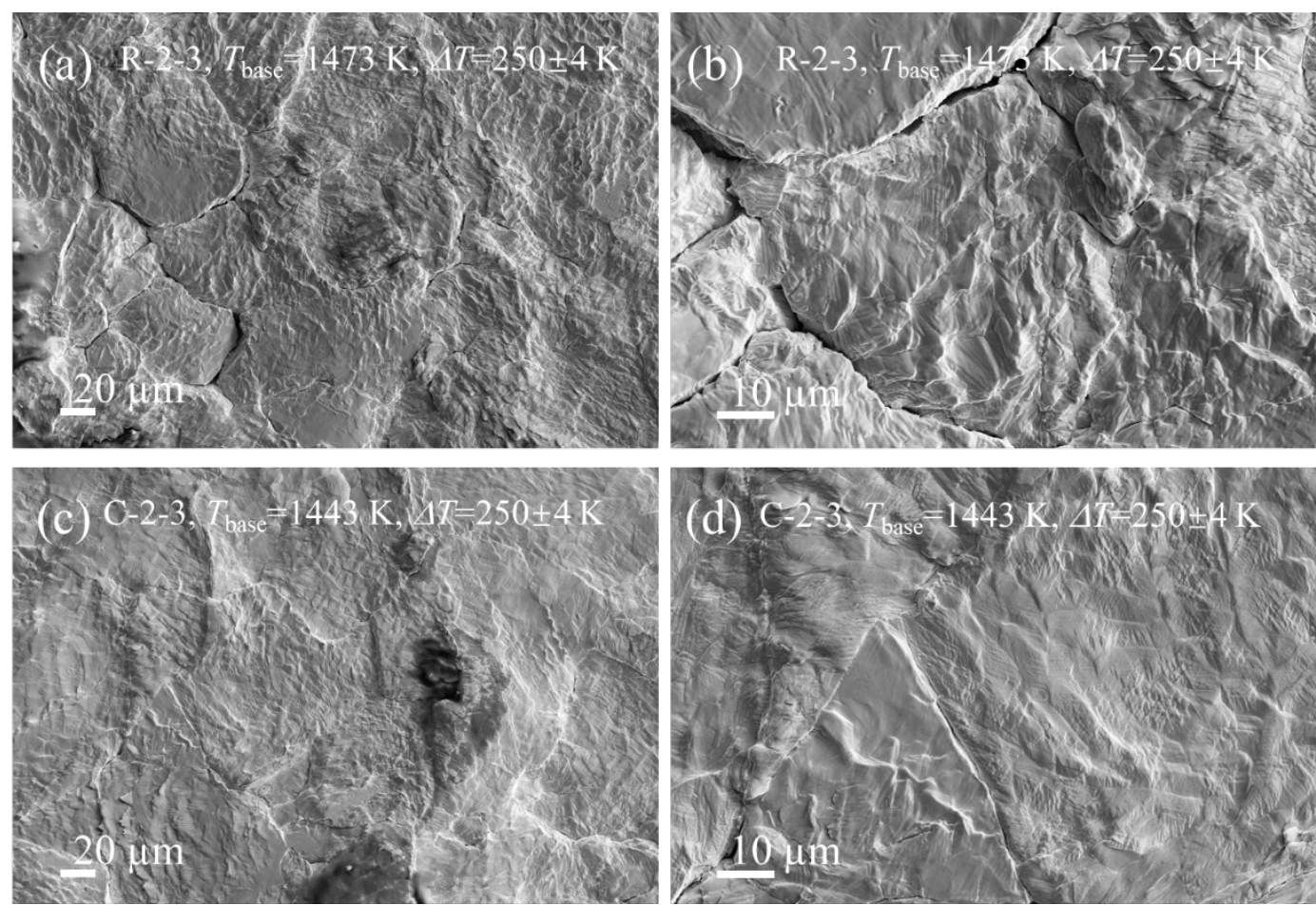
Figure 10. Low-magnification (a)/(c) and high-magnification (b)/(d) images of the exposed R-2-3/C-2-3, captured at the laser beam center. $T_{\text {base }}$ and $\Delta T$ of the R-2-3 were $1473 \mathrm{~K}$ and $250 \pm 4 \mathrm{~K}$, respectively. $T_{\text {base }}$ and $\Delta T$ of the C-2-3 were $1443 \mathrm{~K}$ and $250 \pm 4$ $\mathrm{K}$, respectively. $T_{\text {base }}$ was induced by the steady-state $\mathrm{H}$ plasma, while $\Delta T$ was induced by the laser beam.

To investigate the fatigue performance of the CVD-W coating at a higher temperature, the $T_{\text {base }}$ was increased up to $\sim 1473 \mathrm{~K}$. Figure 10(a) and figure 10(c) shows the surface morphologies of the sample R-2-3 and C-2-3, respectively. Severe plastic deformation could be observed on the surfaces of both samples after exposure. Consistent with the result shown in figure 8 and figure 9, the surface plastic deformation of sample R-2-3 was non-uniform but relatively uniform in sample C-2-3. Moreover, CVD-W exhibits a better crack initiation resistance than commercial W (figure 10(c)-10(d)), probably originated from its ability to deform uniformly. The [001] crystallographic texture developed in CVD-W is therefore beneficial for its thermal fatigue performance.

\subsection{Preparation of $\mathbf{W}$-based mockups}
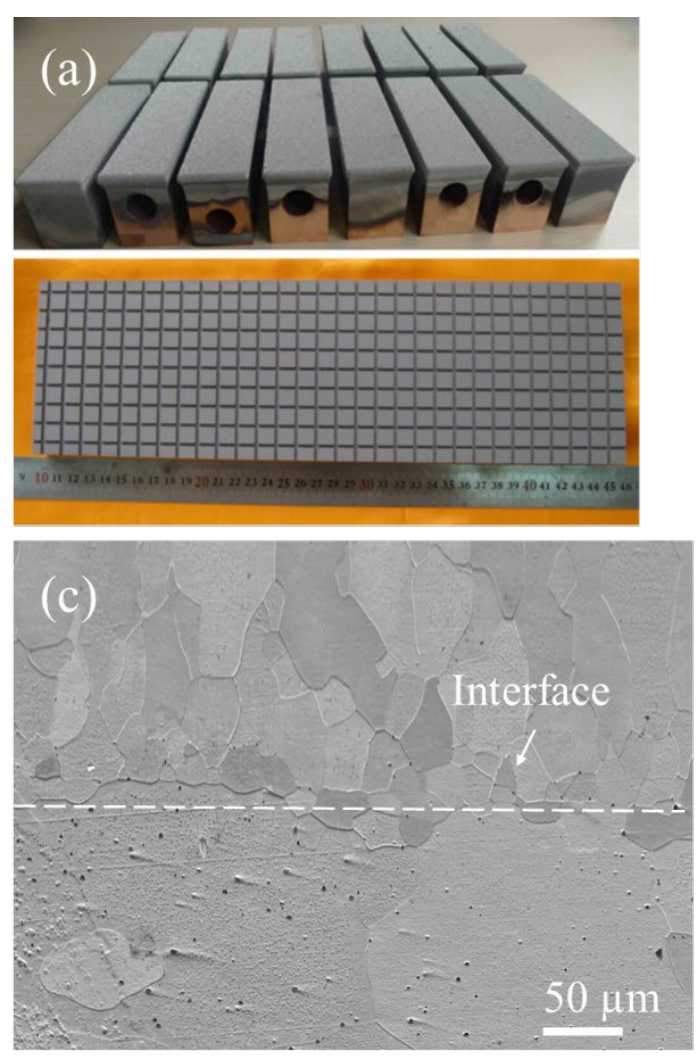
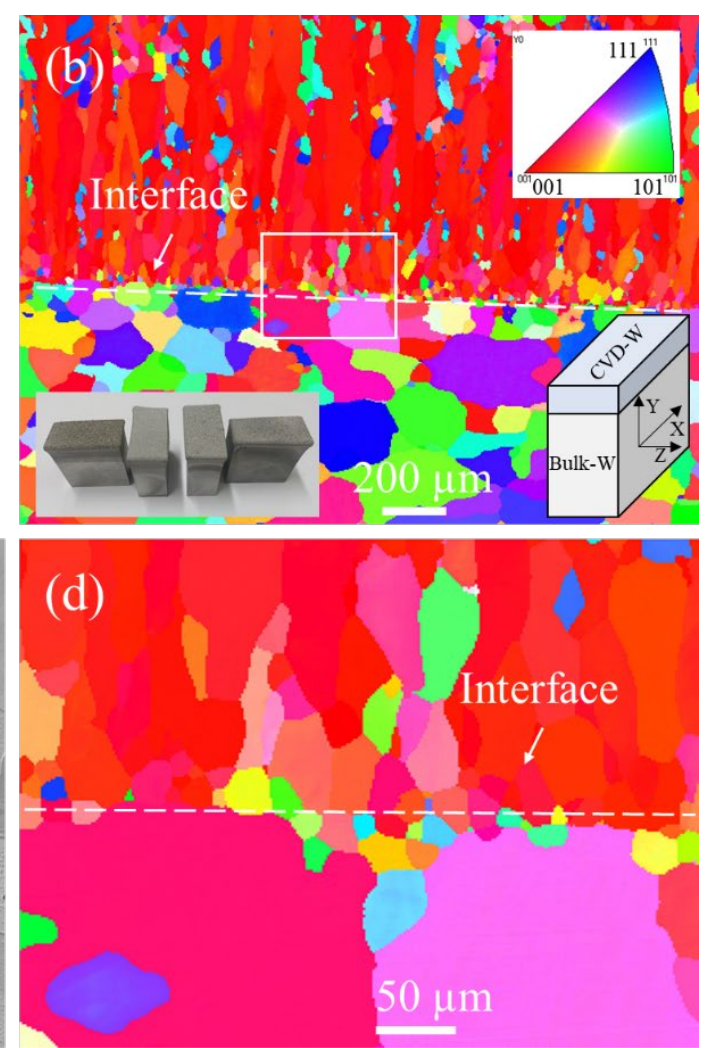

Figure 11. (a) large-scale CVD-W coatings on $\mathrm{Cu}$ alloy (CuCrZr) substrates [14], (b) EBSD image of CVD-W coating deposited on a pure $\mathrm{W}$ substrate (CVD-W/W). The 
CVD-W/W was annealed at $1773 \mathrm{~K}$ for $1 \mathrm{~h}$. (c) High magnification SEM image (c) and the corresponding EBSD image (d) of the location as indicated by the white box in (b). To evaluate the possibility of the preparation of CVD-W based PFMs for the first wall (FW) and divertor, CVD-W coatings have been deposited on different kinds of substrates. For example, the CVD-W/PVD-Si/graphite mockup has been successfully prepared, and the prepared mockup sustained a thermal fatigue testing with an absorbed power density of $4.62 \mathrm{MW} / \mathrm{m}^{2}$ and $5 \mathrm{~s}$ pulse duration for 200 cycles [51]. Flat-type CVD-W/CuCrZr mockups with different interlayers (e.g., W/Cu functionally graded materials (FGM), oxygen-free copper) have also been prepared. The CVDW/FGM/CuCrZr mockup successfully survived a heat flux load of up to $11 \mathrm{MW} / \mathrm{m}^{-2}$ for 1000 cycles [25]. Additionally, the feasibility of the preparation of large-scale CVD$\mathrm{W} / \mathrm{CuCrZr}$ mockups has also been demonstrated [14] (figure 11(a)).

It should be mentioned that the manufacturing cost of CVD-W coatings is very high. Therefore, to benefit from its excellent performance under fusion-relevant conditions as mentioned above, a technical route for the preparation of the CVD-W based mockup has been proposed. Firstly, CVD-W coatings with thickness above $2 \mathrm{~mm}$ are deposited on the commercial pure $\mathrm{W}$ substrate (CVD-W/W). Secondly, a suitable heat treatment is performed to release the residual stress in the CVD-W coating and to increase the bonding strength between the CVD-W coating and W substrate. Thirdly, ITER-like water-cooled monoblocks were manufactured using the processed CVD-W/W. Figure 11(b) shows the EBSD results of the CVD-W/W sample annealed at $1773 \mathrm{~K}$ for $2 \mathrm{~h}$. A photo of the CVD-W/W samples after heat treatment and the illustration of the CVDW/W sample are shown in the lower left and lower right corner of figure 11(b), respectively. No visible cracks and pores were observed near the interface between the CVD-W and W substrate. For the commercial pure $\mathrm{W}$ as shown in the lower part of figure 11(b), a typical recrystallization microstructure could be observed. However, for the CVD-W as shown in the upper part of figure 11(b), the strong [001] texture along the thickness direction of CVD-W is still maintained under the same heat treatment. It is therefore expected that the recrystallization-induced degradation of the service performance of the $\mathrm{W}$ under fusion-relevant heat flux and plasma loadings could be mitigated with the prepared CVD-W/W PFM. Those CVD-W/W samples have been used for the manufacturing of ITER-like water-cooled monoblocks. The evaluation of the thermal handling capability of the monoblocks is undergoing. 


\subsection{Discussion}

Currently, the PM route is the prevalent and highly developed manufacturing technique for the preparation of W-based PFMs. Extensive efforts have been made for the development of alternative manufacturing techniques [52]. For example, to overcome the thickness limitation of the W-based PFMs prepared by the traditional PVD and CVD techniques, atmospheric pressure chemical vapor deposition (APCVD) with a high deposition rate has been successfully developed [25, 53]. The developed CVD-W has advantages such as high purity, excellent thermal conductivity, extraordinary hightemperature stability, and good thermal shock performance, as reviewed in our previous work [14].

D permeability, D plasma irradiation, steady-state, and transient heat flux loading of the thick CVD-W have been investigated in this work. All of them were evolved in the plasma-wall interaction (PWI) of the CVD-W as PFM for fusion application. Compared to the commercial pure $\mathrm{W}$, the CVD-W shows a higher D permeability, mitigated blistering and lower D retention behaviors. Fusion fuel (D and T) inventory in the PFM and its permeation through it into the coolant are of particular concern during the longterm operation of fusion reactors $[18,19]$. A lower D retention in the CVD-W is therefore beneficial for fusion application. However, more attention should be paid to deal with the higher D permeability. Indeed, a sandwich-like structure, which consists of reduced activation ferritic/martensitic steel (structural material), titanium nitride interlayer ( $\mathrm{T}$ barrier), and CVD-W (PFM) has been proposed for the first wall of the DEMO reactor [54]. The interlayer was not only designed to mitigate the stresses between the PFM and the structural materials, but also act as a T permeation barrier.

Previous results showed that blistering of the $\mathrm{W}$ surface had significant grain orientation dependence when exposed to low energy, high flux D plasmas, where grains with normal directions close to the [001] direction exhibited better blistering behavior than others [41-44]. The results of section 3.3 showed that surface modification and plastic deformation of the $\mathrm{W}$ surface also has grain orientation dependence under steady-state and transient heat flux loading. The CVD-W exhibited a better crack initiation resistance than the commercial pure $\mathrm{W}$ counterpart, which implies that the texture may be tailored to improve the thermal fatigue resistance of $\mathrm{W}$.

The CVD-W W coating technique employed in this study can scale up. This was 
demonstrated by fabricating ITER-like monoblocks using a combination of CVD-W and commercial pure W. Microstructural analyses revealed that the interface between CVD-W and commercial pure $\mathrm{W}$ is free of defects (e.g. pores). To further evaluate the quality of the bonding, mechanical tests with specimens containing the interface and high heat flux tests are recommended.

\section{Summary}

Chemical vapor deposition (CVD) was used to prepare $\mathrm{W}$ coatings with millimeter thickness. The prepared CVD-W exhibits high purity, excellent thermal conductivity, extraordinary high-temperature stability, and good thermal shock performance, as reviewed in our previous work [14]. This paper summarized D permeability, D plasma irradiation, and thermal fatigue performance under combined steady-state and transient heat flux loading of the CVD-W. Additionally, large-scale preparation of the CVD-W based PFMs and mockups was performed.

The results showed that the D permeability of CVD-W coating was higher than that of the commercial pure $\mathrm{W}$, even their activation energy values were almost the same. Compared to the pure $\mathrm{W}$ counterpart, mitigated blistering and a lower D retention was observed for the CVD-W. A strong grain orientation dependence of the surface degradation of the $\mathrm{W}$ exposed to steady-state $\mathrm{H}$ plasma and transient laser beam was revealed, where plastic deformation preferentially occurred on the surface grains oriented close to the [101] direction. Moreover, CVD-W exhibits a better crack initiation resistance than commercial $\mathrm{W}$.

Large-scale CVD-W based PFMs and mockups were successfully prepared. Additionally, a technical route for the preparation of the CVD-W based mockup has been proposed to be cost-effective. No cracks and pores could be observed in the CVDW/W interface between the CVD-W and $\mathrm{W}$ substrate after suitable heat treatment. Additionally, the columnar grain structure and strong [001] texture of the CVD-W were maintained after annealing at $1773 \mathrm{~K}$ for $2 \mathrm{~h}$.

\section{Acknowledgments}

We would like to express our great thanks to the Magnum-PSI team for the support of hydrogen plasma experiments at Magnum-PSI. This work is supported by the National 
Natural Science Foundation of China with Grant Nos. 11905045 and 11975092. Z.

Chen acknowledges the support from the Innovation Program of SWIP under Grant No.

201901XWCXRC007. J. Song acknowledges the support from the National Key R\&D

Program of China under Contract No. 2018YFE0312100.

\section{References}

[1] Hirai T. et al 2016 Nuclear Materials and Energy 9 616-622

[2] Merola M. et al 2014 Fusion Eng. Des. 89 890-895

[3] Pitts R. A. et al 2013 J. Nucl. Mater. 438 S48-S56

[4] Ueda Y. et al 2017 Nucl. Fusion 57092006

[5] Panayotis S. et al 2017 Nuclear Materials and Energy 12 200-204

[6] Hirai T. et al 2018 Fusion Eng. Des. 127 66-72

[7] Richou M. et al $2020 \mathrm{~J}$. Nucl. Mater. 542152418

[8] Hirai T. et al 2009 J. Nucl. Mater. 390-391 751-754

[9] Xie Z. M. et al 2018 J. Nucl. Mater. 501 282-292

[10] Chen Z. et al 2020 Nucl. Fusion 60046020

[11] Webb J. et al 2019 Int. J. Refract. Met. Hard Mater. 82 69-80

[12] Ruset C. et al 2011 Fusion Eng. Des. 86 1677-1680

[13] Maisonnier D. et al 2007 Nucl. Fusion 47 1524-1532

[14] Chen Z. et al 2020 Tungsten 2 83-93

[15] Lian Y. et al 2019 J. Nucl. Mater. 513 241-250

[16] Kärcher A. et al 2021 Nuclear Materials and Energy 27100972

[17] Raumann L. et al 2021 Nuclear Materials and Energy 28101048

[18] Skinner C. H. et al 2008 Fusion Science and Technology 54 891-945

[19] Hodille E. A. et al 2017 Nucl. Fusion 57076019

[20] Causet R. A. et al 2001 Phys. Scr. T94 9

[21] Kong X.-S. et al 2015 Acta Mater. 84 426-435

[22] Xu Y. et al 2017 Fusion Eng. Des. 125 239-244

[23] Lian Y. et al 2016 Appl. Surf. Sci. 390 167-174

[24] Lian Y. et al 2014 J. Nucl. Mater. 455 371-375

[25] Lian Y. et al 2013 Fusion Eng. Des. 88 1694-1698

[26] Wang B. et al 2016 J. Nucl. Mater. 470 30-33

[27] De Temmerman G. et al 2013 Fusion Eng. Des. 88 483-487

[28] Morgan T. W. et al 2014 Plasma Phys. Controlled Fusion 56095004

[29] van der Meiden H. J. et al 2016 Appl. Phys. Lett. 109261102

[30] Li Y. et al 2021 Nucl. Fusion 61046018

[31] Stangeby P. C., The Plasma Boundary of Magnetic Fusion Devices, Taylor \& Francis, 2000.

[32] Liu M. et al 2020 Nucl. Fusion 60126034

[33] Guo W. et al 2018 Nucl. Fusion 58106011

[34] Liu F. et al 2014 J. Nucl. Mater. 455 248-252

[35] Piaggi P. M. et al 2015 J. Nucl. Mater. 458 233-239

[36] Zhou H.-B. et al 2010 Nucl. Fusion 50025016

[37] Yu Y. et al 2014 J. Nucl. Mater. 455 91-95

[38] Oudriss A. et al 2012 Acta Mater. 60 6814-6828

[39] von Toussaint U. et al 2011 Phys. Scr. T145 014036

[40] Pintsuk G. et al 2018 Int. J. Refract. Met. Hard Mater. 72 97-103

[41] Chen Z. et al $2016 \mathrm{~J}$. Nucl. Mater. 472 110-117

[42] Chen Z. et al 2018 Acta Mater. 147 100-112

[43] Jia Y. Z. et al 2016 J. Nucl. Mater. 477 165-171

[44] Miyamoto M. et al 2009 Nucl. Fusion 49065035 
[45] Jia Y. Z. et al 2015 J. Nucl. Mater. 457 213-219

[46] Doerner R. P. et al 2016 Nuclear Materials and Energy 9 89-92

[47] Zibrov M. et al 2017 Nucl. Fusion 57046004

[48] Morgan T. W. et al 2020 Phys. Scr. T171 014065

[49] Morgan T. W. et al 2017 Nucl. Fusion 57126025

[50] van Eden G. G. et al 2014 Nucl. Fusion 54123010

[51] Song J. et al $2014 \mathrm{~J}$. Nucl. Mater. 455 531-536

[52] Linsmeier C. et al 2017 Nucl. Fusion 57092007

[53] Song J. et al 2013 J. Nucl. Mater. 442 S208-S213

[54] Cai L. et al 2020 Nucl. Fusion 60096015 